\title{
Dexamethasone treatment in chronic subdural haematoma
}

\author{
P.D. Delgado-López; V. Martín-Velasco; J.M. Castilla-Díez; A. Rodríguez-Salazar; A.M. Galacho-Harriero y
} O. Fernández-Arconada

Servicio de Neurocirugía. Hospital General Yagüe. Burgos.

\section{Summary}

Introduction. Neurosurgeons are familiar with chronic subdural haematoma (CSH), a well-known clinical entity, which is usually treated by some modality of trepanation. Despite the excellent outcomes obtained by surgery, complications may occur, some of which may be potentially severe or fatal. Furthermore, up to $\mathbf{2 5 \%}$ recurrence rate is reported. The authors present a novel approach to the management of CSH based on the use of dexamethasone as the treatment of choice in the majority of cases.

Patients and methods. Medical records of $122 \mathrm{CSH}$ patients were retrospectively reviewed. At admission, symptomatic patients were classified according to the Markwalder Grading Score (MGS). Those scoring MGS 1-2 were assigned to the Dexamethasone protocol $(4 \mathrm{mg}$ every $8 \mathrm{~h}$, re-evaluation after $48-72 \mathrm{~h}$, slow tapering), and those scoring MGS 3-4 were, in general, assigned to the Surgical protocol (single frontal twistdrill drainage to a closed system, without irrigation). Patients were followed in the Outpatient Office with neurological assessment and serial CT scans.

Results. Between March 2001 and May 2006, 122 consecutive CSH patients $(69 \%$ male, median aged of 78, range 25-97) were treated. Seventy-three percent of the patients exhibited some kind of neurological defect (MGS 2-3-4). Asymptomatic patients (MGS 0) were left untreated. Initial treatment assignment was: 101 dexamethasone, 15 subdural drain, 4 craneotomy and 2 untreated. Twenty-two patients on dexamethasone ultimately required surgical drain $(21.8 \%)$. Favourable outcome (MGS 0-1-2) was obtained in 96\% and 93.9\% of those treated with dexamethasone and surgical drain, respectively. Median hospital stay was 6 days (range 141) for the dexamethasone group and the whole series, and 8 days (range 5-48) for the surgical group. Overall mortality rate was $0.8 \%$ and re-admissions related to the haematoma reached $14.7 \%$ (all maintained or

Recibido: 4-08-07. Aceptado: 23-01-09 improved their MGS). Medical complications occurred in 34 patients $(\mathbf{2 7 . 8 \%})$, mainly mild hyperglycemic impairments. Median outpatient follow up was 25 weeks (range 8-90), and two patients were lost.

Discussion. The rationale for the use of dexamethasone in CSH lies in its anti-angiogenic properties over the subdural clot membrane, as it is derived from experimental studies and the very few clinical observations published. Surgical evacuation of CSH is known to achieve excellent results but no well-designed trials compare medical versus surgical therapies. The experience obtained from this series lets us formulate some clinical considerations: dexamethasone is a feasible treatment that positively compares to surgical drain (and avoided two thirds of operations); the natural history of CSH allows a 48-72h dexamethasone trial without putting the patient at risk of irreversible deterioration; eliminates all morbidity related to surgery and recurrences; does not provoke significant morbidity itself; reduces hospital stay; does not preclude ulterior surgical procedures; it is well tolerated and understood by the patient and relatives and it probably reduces costs. The authors propose a protocol that does not intend to substitute surgery but to offer a safe and effective alternative.

Conclusion. Data obtained from this large retrospective series suggests that dexamethasone is a feasible and safe option in the management of CSH. In the author's experience dexamethasone was able to cure or improve two thirds of the patients. This fact should be confirmed by others in the future. The true effectiveness of the therapy as compared to surgical treatment could be ideally tested in a prospective randomized trial.

KEY WORDS: Chronic subdural haematoma. Dexamethasone. Nonoperative treatment. Glucocorticoids.

Tratamiento con dexametasona del hematoma subdural crónico 
Introducción. El hematoma subdural crónico (HSC) es una entidad clínica bien conocida por los neurocirujanos, cuyo tratamiento habitual es la evacuación del mismo a través de alguna modalidad de trepanación. A pesar de los excelentes resultados así obtenidos, pueden ocurrir diversas complicaciones, algunas de las cuales son potencialmente graves o mortales. Además, la tasa de recidivas puede alcanzar el $25 \%$ de los casos. Presentamos una aproximación novedosa al manejo del HSC, basada en la utilización de dexametasona como tratamiento de elección en la gran mayoría de los pacientes.

Pacientes y métodos. Se analizaron los historiales médicos de 122 pacientes consecutivos diagnosticados de HSC. Al ingreso todos los pacientes sintomáticos fueron clasificados mediante la Escala de Puntuación de Markwalder (EPM). Aquellos con EPM de 1-2 fueron asignados al Protocolo de Dexametasona (4mg cada $8 \mathrm{~h}$, re-evaluación a las $72 \mathrm{~h}$ y disminución progresiva de dosis) y aquellos con EPM de 3-4 se asignaron, en general, al Protocolo Quirúrgico (único mini-trépano tipo twist-drill frontal, sin irrigación y drenaje a sistema cerrado). El seguimiento clínico se realizó mediante TAC y valoración neurológica en la consulta externa.

Resultados. En el período entre Marzo 2001 y Mayo 2006, se trataron 122 pacientes con HSC (69\% varones) con una mediana de edad de 78 años (rango 25-97). El 73\% de los pacientes presentaban algún déficit neurológico (EPM 2-3-4). No se trataron pacientes asintomáticos (EPM 0). La asignación inicial de tratamientos fue: 101 dexametasona, 15 drenaje subdural, 4 craneotomía y 2 no recibieron tratamiento. Precisaron drenaje 22 pacientes inicialmente asignados a dexametasona (21.8\%). Se obtuvo resultado favorable (EPM 0-12) en el $96 \%$ y $93.9 \%$ de los tratados con dexametasona y drenaje, respectivamente. La mediana de estancia fue de 6 días para el grupo de dexametasona y para la serie al completo (rango 1-41), y de 8 días para el grupo intervenido (rango 5-48). La mortalidad global fue del $0.8 \%$ y la proporción de reingresos debido al HSD del $\mathbf{1 4 . 7 \%}$ (todos mejoraron o estabilizaron su EPM). Ocurrieron complicaciones médicas en 34 pacientes $(27.8 \%$ ), fundamentalmente descompensaciones hiperglucémicas leves. El seguimiento mediano extrahospitalario de la serie fue de 25 semanas (rango 8-90), con dos únicas pérdidas.

Discusión. La utilización de dexametasona en el HSC se basa en sus propiedades antiangiogénicas sobre la membrana del coágulo subdural, según se desprende de estudios experimentales y de las muy escasas observaciones clínicas publicadas. El tratamiento quirúrgico del HSC es conocido que obtiene excelentes resultados, aunque no existen ensayos bien diseñados que comparen ambas modalidades terapéuticas. La experiencia que aporta esta serie nos permite realizar una serie de consideraciones clínicas: el tratamiento del HSC con dexametasona es factible $y$ se compara positivamente con el tratamiento quirúrgico (evitó dos tercios de las intervenciones en nuestra serie); creemos que la historia natural del $\mathrm{HSC}$ permite un período de prueba con dexametasona (48-72h) sin someter a riesgo de deterioro irreversible al paciente; se elimina toda la morbilidad asociada a las intervenciones y las recidivas; no provoca complicaciones significativas; reduce la estancia media; no impide ni perjudica un ulterior tratamiento quirúrgico; es una terapia bien tolerada y entendida por el paciente y sus acompañantes $y$, posiblemente, abarata costes. Los autores proponen un protocolo de manejo que no pretende sustituir al tratamiento quirúrgico sino ofrecer una alternativa efectiva y segura.

Conclusión. Los datos obtenidos de esta larga serie retrospectiva sugieren que la utilización de dexametasona en el HSC es una opción factible y segura. En nuestra experiencia, curó o mejoró a dos tercios de todos los pacientes, hecho que debe ser corroborado por otros autores. La verdadera efectividad de esta terapia podría ser objeto, idealmente, de un ensayo aleatorizado y prospectivo que compare el tratamiento quirúrgico con el corticoideo.

PALABRAS CLAVE: Hematoma subdural crónico. Dexametasona. Tratamiento conservador. Glucocorticoides.

\section{Introduction}

Chronic subdural haematoma (CSH) is a well-defined clinical condition consisting in a slowly progressive accumulation of liquefied blood within the subdural space. Such collection may, eventually, produce hemisphere compression and result in ultimate brain herniation. It is diagnosed in one or two persons in every 100.000 in the general population per year ${ }^{10,25}$. The incidence is higher in the elderly (up to 58 per 100.000 in people older than seventy), and in patients with a history of alcohol abuse or coagulation disturbance. Minor head trauma a few weeks before presentation is a common antecedent. Slow venous bleeding and the creation of neo-membranes around the subdural clot are some recognized pathogenic features in the development of $\mathrm{CSH}^{6,14,15,16}$.

Neurosurgeons around the globe are familiar with this condition and many of them consider symptomatic $\mathrm{CSH}$ a clinical scenario that requires prompt specialized evaluation and neurosurgical intervention, often on an emergency basis. At present, burr-hole or twist-drill craniostomy and drainage are the most widely used surgical 
techniques ${ }^{19,24,25,31}$. Neurological outcome after surgical evacuation of CSH is known to be remarkably favourable in the great majority of patients ${ }^{18,30}$. Nevertheless, wound infection, subdural empyema, tension pneumocephalus, brain contusion, subdural or epidural haematoma, intracerebral haemorrhage, catheter penetration of the brain and even death may occur after surgery ${ }^{18}$. Additionally, up to $25 \%$ of patients need to be re-operated on due to re-accumulation of blood ${ }^{7,10,20,25,29}$. Surprisingly, despite this tendency towards recurrence and its related morbidity, prognosis in CSH seems to be more influenced by the age of the patient and his/her presenting neurological status than by the type of intervention performed ${ }^{4,10,11}$. Thus, for adequate evaluation and analysis of outcome, it is appropriate to classify patients according to functional clinical scales such as Markwalder's grading score $(\mathrm{MGS})^{17}$. Nonoperative measures, such as, hypertonic or hyperosmolar solutions and systemic glucocorticoids have been used in CSH with favourable results ${ }^{6,25,26,30}$. Noticeably, the literature concerning these therapies consists of small case series and very few clinical observations ${ }^{1-3,13,22,23,26,27,29,30}$.

Thanks to a widespread availability of modern neuroimaging, many cases of CSH with few or no symptoms at all are incidentally found. Although the overall morbidity and mortality associated with surgical drainage are low, it seems reasonable to offer less aggressive measures, at least, to this subset of patients. Successful resolution of $\mathrm{CSH}$ either spontaneously or after medical treatment has been reported before, even for severely impaired patients ${ }^{25,30}$. Nevertheless, recommendations favoring non-operative treatment of CSH are supported by scarce literature. The natural history of untreated or medically managed $\mathrm{CSH}$ is not well known. In fact, very few papers discuss on the advantages and disadvantages of surgical versus medical therapy and, virtually none of them compare the outcomes and morbidity-mortality in a well-designed clinical trial. Systemic steroid therapy has been used in $\mathrm{CSH}$ as an alternative to surgical evacuation in selected patients. The rationale for its use lies on the complex effects of corticoids over the clot membrane and neovascularization ${ }^{14,15,16,28}$.

In our department, we have been using dexamethasone for the treatment of symptomatic CSH since 1995. A protocol was developed in 2001 for its systematized use. The aim of this paper is to describe our large single-institution experience and to discuss the effectiveness and safety of corticotherapy in $\mathrm{CSH}$ and its implications for the clinical practice. The authors propose a novel approach to the management of $\mathrm{CSH}$, considering steroid therapy a reliable first therapeutic option in the vast majority of cases, thus avoiding many (in about two thirds of the patients) unnecessary surgical procedures.

\section{Patients and methods}

Data from the medical records of $122 \mathrm{CSH}$ patients treated in our department was retrospectively reviewed and analyzed. Upon admission, all patients were graded according to their functional neurological condition. The Markwalder Grading Score is a well-recognized scale that takes into account the presence or absence of neurological symptoms, focal defects and the level of consciousness ${ }^{17}$.

According to this classification, patients scoring MGS 1-2 (alert, orientated and those drowsy or disorientated with possible variable neurological deficits) were assigned to the Dexamethasone Protocol whereas patients in MGS 3-4 (stuporous or comatose) were, in general, assigned to the Surgical Protocol. Some patients in grades 3-4 were also initially treated with dexamethasone as it is discussed below. No patient was left untreated in the case of severe neurological deterioration or due to extreme age. Our policy is not to treat asymptomatic CSH patients (MGS 0), but to follow them up. Non contrast cranial CT scan was used for initial diagnosis and follow up in all cases.

\section{Dexamethasone protocol}

It consists in the administration of $4 \mathrm{mg}$ of dexamethasone every eight hours, either oral or intravenous; bed rest; oral diet if possible (or through nasogastric tube) or fluid reposition, depending on the level of consciousness; omeprazole (20 mg per day); and prophylaxis of thrombophlebitis with either subcutaneous enoxaparin (20-40 mg/ day) and/or lower-limbs pneumatic compression device. Patient's neurological status is checked every day and the effectiveness of corticotherapy is re-evaluated after 48-72 hours. Those patients not improving their MGS are proposed for the Surgical Protocol. The rest are either allowed to ambulate or discharged and dexamethasone is slowly tapered (reducing $1 \mathrm{mg}$ per day every three days) until complete withdrawal. Clinical and radiological evaluation is performed after 6 weeks (in the Outpatient Office) and further on until complete cure or clinical-radiological stabilization.

\section{Surgical protocol}

We advocate for the performance of a single (or double, in bilateral CSHs) twist-drill mini-craniostomy over the affected hemisphere, preferably in the frontal region. The procedure is done with the patient supine under local anaesthesia and mild sedation. We use a 5-6 mm diameter manual drill intending to create a small burr hole as parallel as possible to the inner table of the skull in order to minimize the risk of brain penetration. A ventricular catheter is inserted in the subdural space and a moderate quantity of liquid is allowed to exit until the initial overpressure is 
Table 1

Previous history, symptoms and signs at presentation

\begin{tabular}{|l|c|c|}
\hline \multicolumn{1}{|c|}{ Previous history } & Symptoms & Signs \\
\hline 61 Previous head trauma & 43 Headache & 42 Hemiparesis \\
35 Hypertension & 38 Instability & 24 Disoriented \\
22 Anticoagulated & 16 Dizziness, nausea, vomits & 23 Speech impairment \\
21 Cardiopathy, valvulopathy & 8 Seizures & 21 Cognitive impairment \\
20 Type2 diabetes & & 5 Comatose \\
18 Atrial fibrillation & & \\
17 Previous stroke & & \\
11 Dementia & & \\
7 Chronic alcohol abus & & \\
\hline
\end{tabular}

Table 2

Markwalder grading scale at admission

\begin{tabular}{|c|c|c|}
\hline & $\mathbf{N}$ & $\mathbf{\%}$ \\
\hline Grade 0 & 0 & 0 \\
\hline Grade 1 & 33 & 27,1 \\
\hline Grade 2 & 62 & 50,8 \\
\hline Grade 3 & 19 & 15,6 \\
\hline Grade 4 & 8 & 6,5 \\
\hline
\end{tabular}

(Markwalder Grading Scale: Grade 0: Neurologically normal; Grade 1: Alert and orientated: absence of mild symptoms such as headache, or mild neurological deficit such as reflex asymmetry; Grade 2: Drowsy or disorientated, or variable neurological deficit such as hemiparesis; Grade 3: Stuporous, but responding appropriately to noxious stimuli; several focal signs such as hemiplegia; Grade 4: Comatose with absent motor responses to painful stimuli; decerebrate or decorticate posturing.)

relieved. The catheter is connected to a collecting device located at least $20-30 \mathrm{~cm}$ below the patient's head, letting the fluid out drop-by-drop. The bloody CSF outflow rate is thus controlled intending to avoid pneumocephalus or contralateral haematomas. No subdural irrigation is performed. The drainage is maintained 48-72 hours. Surgical time rarely exceeds 10-15 minutes. Antimicrobial prophylaxis is maintained as long as the catheter remains inserted (intravenous Cephazolin 2gr/8h or Vancomycin 1g/12h). Clinical re-evaluation is done after drainage withdrawal. Patients not clearly improving after drainage are initiated on dexamethasone as an adjuvant therapy. Some cases needed a second drainage due to re-accumulation of liquid and very few underwent craniotomy and membranectomy. The latter technique was reserved for unresponsive and rapidly deteriorating patients. The same follow up protocol as in medical patients applies in this group.

This retrospective case series includes 122 consecutive $\mathrm{CSH}$ patients recruited in the time period from March 2001 to May 2006. Follow up was complete for the whole series except for two patients who changed residency and were lost. Clinical outcome is described below on the basis of the last history note written by the surgeon who treated the patient, so that every patient achieved one of three possible endpoints: complete cure, clinical stabilization not requiring further treatment or exitus. Data analysis does not include p-values for statistical parameters since the design of this study (a priori assignment of treatments) and sample size (small $\mathrm{N}$ values in subsets) do not allow direct comparisons among the different treatment groups.

\section{Results}

In the time period above mentioned, 122 consecutive patients with the diagnosis of CSH were treated in our department. Five neurosurgeons participated in their management. The distribution by sex was: 84 males $(69 \%)$ and 38 women $(31 \%)$, corresponding to a $2.2: 1$ ratio male:female. The median age of the series was 78 years (range 25-97); 47 patients were older than 80 and 98 patients were older than 70 . Clinical data regarding previous history, symptoms and signs at presentation are listed in Table 1.

Fifty percent of the patients referred a mild head trauma in the weeks/months before admission. The commonest 
Table 3

Initial treatment assignment according to Markwalder grading scale

\begin{tabular}{|c|c|c|c|c|}
\hline & Dexamethasone & drain & craniotomy & untreated \\
\hline Grade 0 & 0 & 0 & 0 & 0 \\
\hline Grade 1 & 29 & 2 & 1 & 1 \\
\hline Grade 2 & 54 & 5 & 2 & 0 \\
\hline Grade 3 & 15 & 3 & 1 & 0 \\
\hline Grade 4 & 3 & $\mathbf{1 5}$ & $\mathbf{4}$ & $\mathbf{2}$ \\
\hline
\end{tabular}

(Markwalder Grading Scale: Grade 0: Neurologically normal; Grade 1: Alert and orientated: absence of mild symptoms such as headache, or mild neurological deficit such as reflex asymmetry; Grade 2: Drowsy or disorientated, or variable neurological deficit such as hemiparesis; Grade 3: Stuporous, but responding appropriately to noxious stimuli; several focal signs such as hemiplegia; Grade 4: Comatose with absent motor responses to painful stimuli; decerebrate or decorticate posturing.)

Table 4

Outcome measured by the MGS according to treatment modality

\begin{tabular}{|c|c|c|c|c|c|c|c|}
\hline $\mathbf{N}$ & & $\mathbf{0}$ & 1 & 2 & 3 & 4 & Exitus \\
\hline 73 & Dxm & 56 & 10 & 5 & 2 & - & - \\
\hline 22 & $D x m+D$ & 10 & 8 & 3 & - & - & 1 \\
\hline 3 & $D x m+D+C$ & - & - & 2 & 1 & - & - \\
\hline 3 & $D x m+D x m$ & 2 & 1 & - & - & - & - \\
\hline \multicolumn{8}{|c|}{$(101)$} \\
\hline 11 & $D$ & 5 & 6 & - & - & - & - \\
\hline 2 & $D+D$ & 1 & - & - & 1 & - & - \\
\hline 2 & $D+D x m$ & 1 & - & 1 & - & - & - \\
\hline \multicolumn{8}{|c|}{ (15) } \\
\hline 3 & $C$ & 2 & 1 & - & - & - & - \\
\hline 1 & $C+D$ & - & - & - & 1 & - & - \\
\hline \multicolumn{8}{|c|}{ (4) } \\
\hline 2 & Untreated & 2 & - & - & - & - & - \\
\hline \multicolumn{8}{|c|}{ (2) } \\
\hline 122 & & 79 & 26 & 11 & 5 & $\mathbf{0}$ & 1 \\
\hline
\end{tabular}

(Dxm: Dexamethasone; D: Subdural Drain; C: Craniotomy)

antecedents were hypertension, anticoagulation medication intake, cardiomyopathy and type-2 diabetes. Patients presented with headache and instability in the majority of cases. Neurological defects included confusion, motor disturbance and depressed level of consciousness. No cranial nerve disturbance was ascertained in the series. 
Table 5

Outcome measured by the MGS in the midline-shift subgroup

\begin{tabular}{|c|c|c|c|c|c|c|c|}
\hline $\mathbf{N}$ & & $\mathbf{0}$ & 1 & 2 & 3 & 4 & Exitus \\
\hline 29 & Dxm & 18 & 6 & 3 & 2 & - & - \\
\hline 12 & $D x m+D$ & 5 & 4 & 2 & - & - & 1 \\
\hline 3 & $D x m+D+C$ & - & - & 2 & 1 & - & - \\
\hline 2 & $D x m+D x m$ & 1 & 1 & - & - & - & - \\
\hline \multicolumn{8}{|c|}{ (46) } \\
\hline 7 & $D$ & 2 & 5 & - & - & - & - \\
\hline 2 & $D+D$ & 1 & - & - & 1 & - & - \\
\hline 2 & $D+D x m$ & 1 & - & 1 & - & - & - \\
\hline \multicolumn{8}{|c|}{ (11) } \\
\hline 3 & $C$ & 2 & 1 & - & - & - & - \\
\hline 1 & $C+D$ & - & - & - & 1 & - & - \\
\hline \multicolumn{8}{|c|}{ (4) } \\
\hline 0 & Untreated & - & - & - & - & - & - \\
\hline \multicolumn{8}{|c|}{ (0) } \\
\hline 61 & & 30 & 17 & 8 & 5 & $\mathbf{0}$ & 1 \\
\hline
\end{tabular}

(Dxm: Dexamethasone; D: Subdural Drain; C: Craniotomy)

\section{Treatments applied}

Initial treatment assignation (indicated by the neurosurgeon responsible for the patient) was as follows: 101 patients underwent the Dexamethasone protocol, 15 patients were operated on by subdural drain, 4 patients underwent craniotomy and 2 patients did not receive any treatment (they refused any medical or surgical therapy; they were just observed). After being classified by the MGS (Table 2), patients in grade 2 were the most common and $72,9 \%$ of patients exhibited some kind of neurological defect (grades 2-3-4). Treatment assignation depending on the MGS at admission is shown in Table 3. No patient was treated in grade 0 , that is, asymptomatic.

Cranial CT findings were recorded according to laterality, midline shift, density and the presence of membranes within the haematoma. Thus, 83 patients harboured a unilateral CSH (68\%) and 39 were bilateral; $50 \%$ of the CSH were able to produce midline shift of some degree; 60 haematomas were hypodense, 29 hypodense-hyperdense with areas of recent bleeding, 3 were predominantly hyperdense and 30 were isodense-subacute. Membranes (hyperdense trabecular walls) were ascertained in 6 patients. According to midline shift, treatment distribution was as follows: among those harbouring haematomas producing midline shift (61), 46 patients received dexamethasone treatment, 11 were surgically drained and 4 underwent craniotomy; among those without midline shift (61), 55 were treated with dexamethasone, 4 were drained and 2 were left untreated. There were 22 patients initially assigned to dexamethasone that eventually needed subdural drain $(21.8 \%)$ and 3 more underwent a second drain and posterior craniotomy. Two patients that were initially treated by subdural drain, needed a second drain (13.3\%) but none of them ended in craniotomy.

\section{Description of results}

Treatment outcome was classified according to the MGS at discharge. The two patients left untreated resolved spontaneously without sequelae (MGS $2 \rightarrow 0$ and $1 \rightarrow 0$, respectively).

Favourable results (grades $0+1+2$, that is, without important neurological deficit) were obtained in the great 

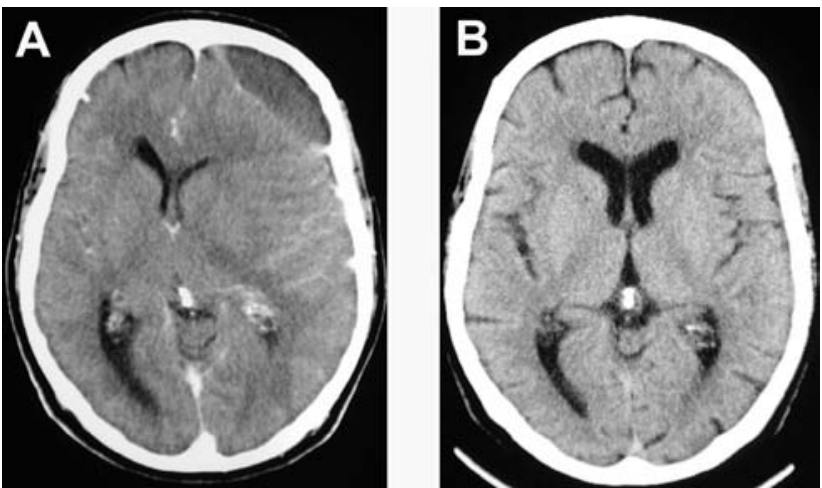

Figure 1. A: left frontal CSH causing midline shift in a 72 year-old male presenting with confusion, dysphasia and hemiparesis. B: Complete resolution of the haematoma three months after initiation of dexamethasone.
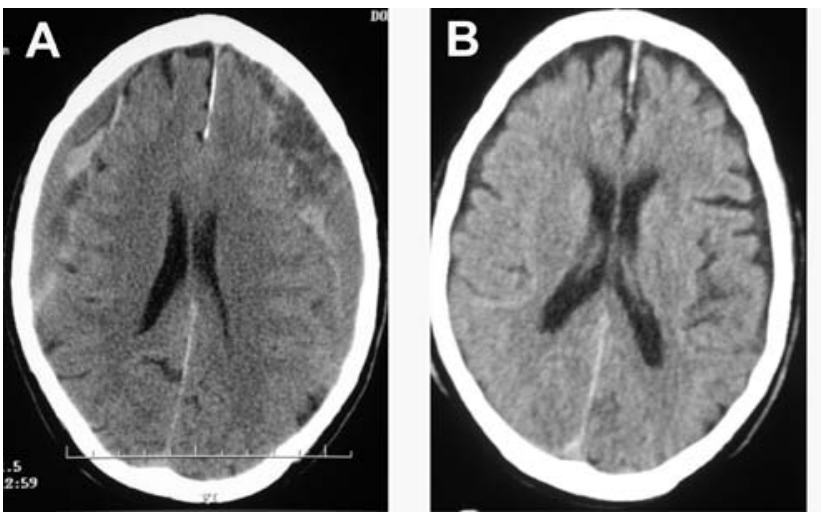

Figure 3. A: mixed density bilateral CSH with membranes and signs of early re-bleeding in a 77 year-old female presenting stuporous and a history of progressive gait and cognitive impairment. Dexamethasone treatment was administered as in the proposed protocol. B: Complete resolution after 18 weeks follow up.

majority of patients treated with dexamethasone (97 out of $101,96 \%$ ), subdural drain (14 out of $15,93.3 \%)$ and craniotomy ( 3 out of $4,75 \%$ ), as it is referred to in Table 4. Median hospital stay was 6 days (range 1-41) for the dexamethasone group; 8 days (range 5-28) for the Drain group; 7 days (range 4-27) for the Craniotomy group; and 6 days (range 1-41) for the whole series. The untreated patients who refused active treatment remained 2 and 8 days in hospital (even though no specific medication was administered they both spontaneously improved to MGS $0)$. Interestingly, patients presenting with haematomas producing midline shift (61 patients) also obtained good results, both in the dexamethasone group (41 out of 46, $91.3 \%$ ) and among those operated on (10 out of $11,90 \%$ in the drain subgroup and 3 out of $4,75 \%$ in the craniotomy subgroup) as it is detailed in Table 5.

Although clinical improvement begun early after corti-
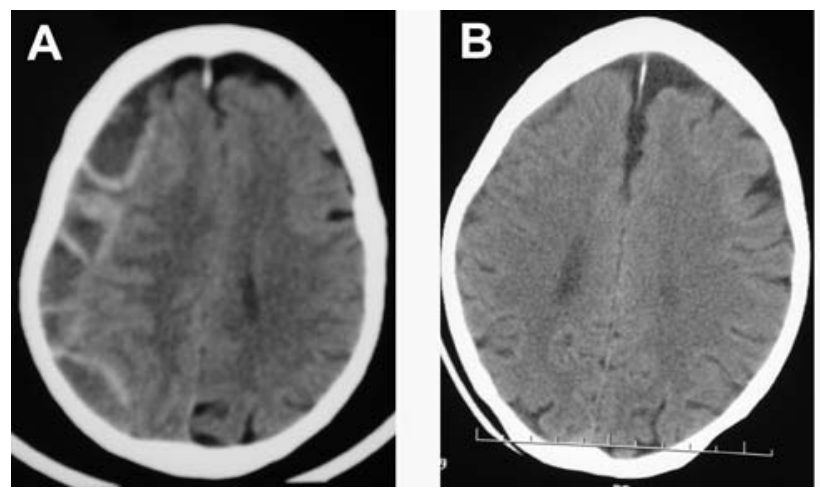

Figure 2. A: hypodense unilateral CSH and dense trabeculae within the haematoma producing midline shift in a 68 year-old female presenting with depressed level of consciousness, hemiparesis and progressive gait impairment. Dexamethasone treatment was initiated. B: Complete resolution of the haematoma after four months follow up.
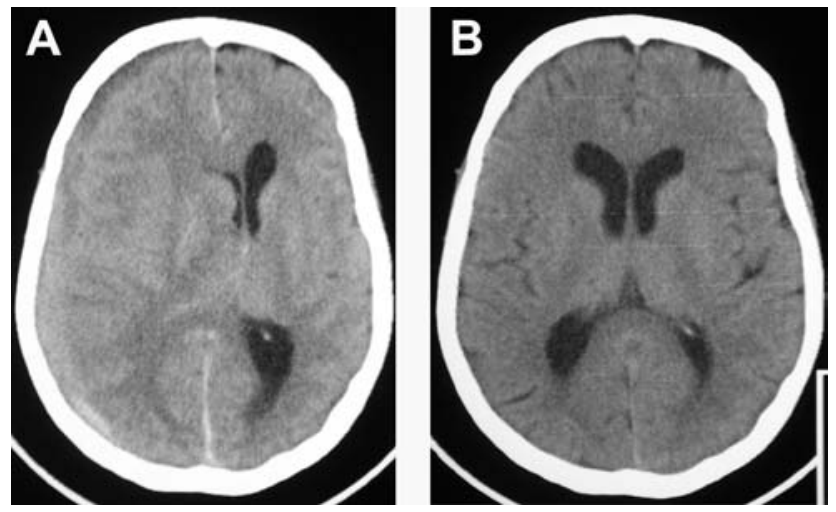

Figure 4. A: mixed density CSH with marked midline shift in a 69 year-old female presenting with headache, vomiting, hemiparesis and drowsiness. B: Complete resolution of the haematoma three and a half months after initiating dexamethasone treatment.

coid initiation, radiological resolution or stabilization was achieved weeks or months later on during the outpatient follow up period. Remarkably, some patients needed up to 6 months or even more until complete CT image resolution occurred. After hospital discharge, median follow up time was 25 weeks (range 8-90) for the whole series, excluding two patients that were lost after discharge. It is remarkable that the MGS obtained at the moment of discharge remained stable over time as it was ascertained by reviewing the history notes from the Outpatient Office, except for those patients who were re-admitted in our department due to deterioration attributable to the haematoma (see below). Figures 1 to 6 are paradigmatic examples of some excellent clinical outcomes (MGS 0) and radiological resolutions following dexamethasone therapy alone in patients harbouring various types of CSHs. 

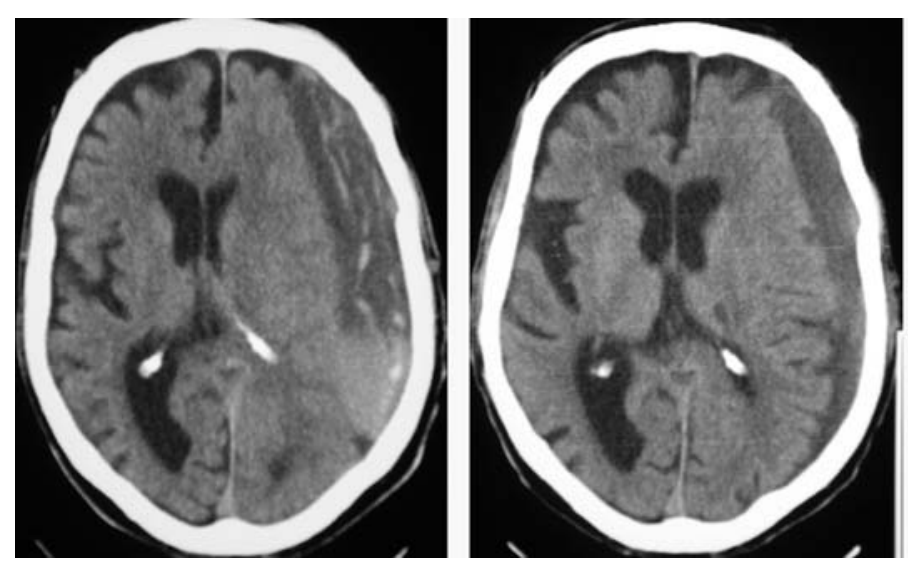

2009; 20: 346-359
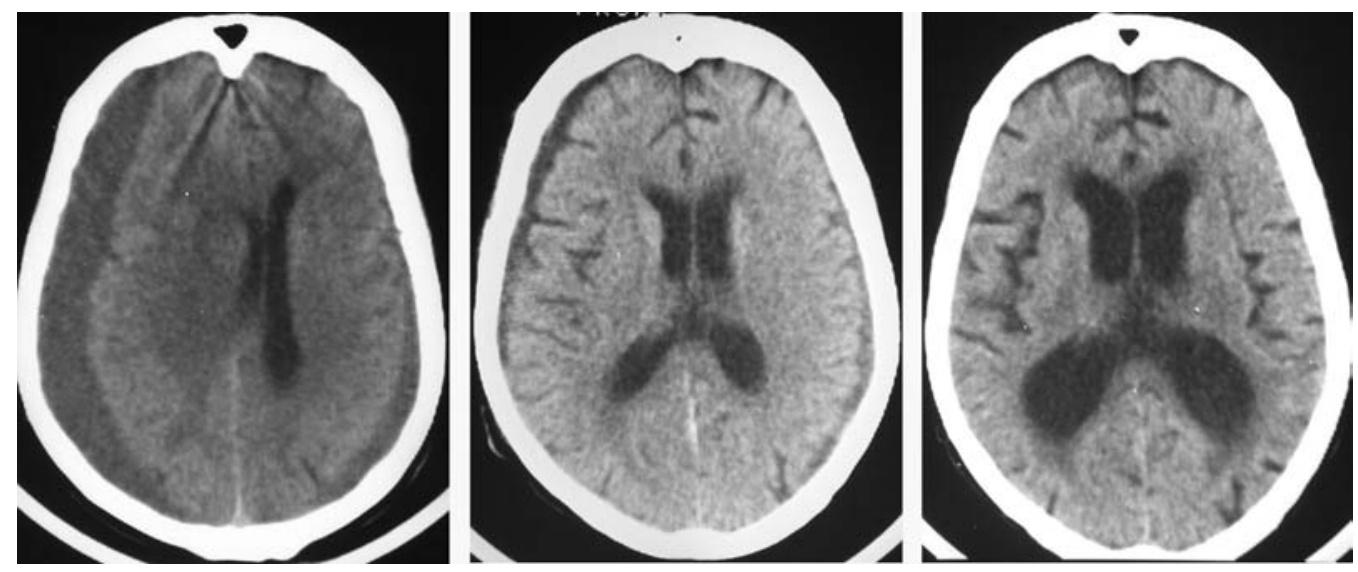

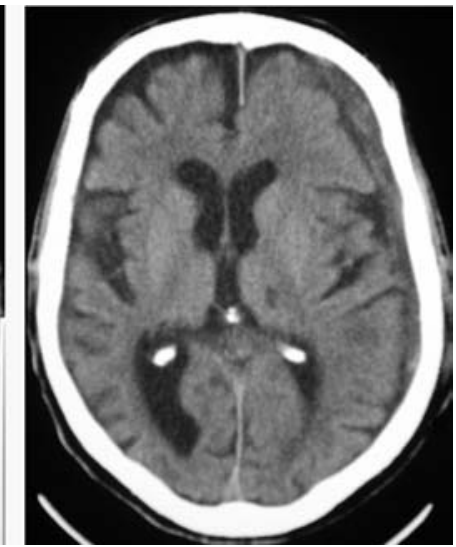

Figure 5. Radiological sequence of a marked unilateral $\mathrm{CSH}$ with signs of re-bleeding and membranes in an 89 yearold male presenting with confusion, aphasia and intense headache. Images were taken at admission, three months and six and a half months after initiating dexamethasone treatment.

Figure 6. Radiological sequence of a bilateral hypodense CSH in a 91 year-old female presenting with depressed level of consciousness, headache and tetraparesis. Images were taken at admission, 41 days and 6 months after initiating dexamethasone therapy.

He was 79 years old presenting with hemiparesis and dysphasia with a small hypodense unilateral CSH that completely resolved with dexamethasone after 33 days of hospital stay. The median stay of patients who presented any complication was 8 days (range 1-41).

\section{Discussion}

The incidence of CSH in the general population is estimated to be $1-3 / 100.000$ per year. The tendency towards ageing in western countries is probably increasing this figure. Incidence rises to 7-13/100.000 per year in older than 65 and as high as 17-58/100.000 per year in older than 7010,24. A two-fold increase in incidence is expected over the next fifty years ${ }^{24}$.

The series presented is, to our knowledge, the largest published to date on CSH managed mainly by glucocorticoids (see Table 8). Minor head trauma was a common antecedent to the diagnosis $(50 \%)$ and presentation occurred mainly in the form of headache and instability along with hemiparesis and altered mental status. No oculomotor disturbance could be ascertained in the whole series, a rare sign previously described ${ }^{21}$. Our policy is not to treat grade 0 (asymptomatic) patients. The great majority of patients in grades 1-2-3 underwent the dexamethasone protocol, including some in grade 4. 
Table 6

Adverse events during hospitalization

\begin{tabular}{|c|c|}
\hline 18 & $\begin{array}{l}\text { Hyperglycemias } \\
10 \text { mild, needed minimum adjustment } \\
8 \text { severe, needed insulin administration }\end{array}$ \\
\hline 11 & $\begin{array}{l}\text { Nosocomial infections } \\
7 \text { urinary tract bacterial infections } \\
2 \text { nosocomial pneumonia } \\
1 \text { oral and urinary candidiasis } \\
1 \text { gastroenteritis }\end{array}$ \\
\hline 3 & $\begin{array}{l}\text { Thromboembolism } \\
1 \text { bilateral pulmonary embolism, } 1 \text { unconfirmed } \\
1 \text { deep venous thrombosis }\end{array}$ \\
\hline 3 & $\begin{array}{l}\text { Cardiac impairment } \\
1 \text { pulmonary oedema } \\
1 \text { acute respiratory insufficiency } \\
1 \text { bradycardia due to digital intoxication }\end{array}$ \\
\hline 1 & Stroke in patient with atrial fibrillation \\
\hline 1 & $\begin{array}{l}\text { Gastrointestinal haemorrhage that needed endos- } \\
\text { copic sclerosis }\end{array}$ \\
\hline 1 & $\begin{array}{l}\text { ADH inappropriate secretion responding to water } \\
\text { restriction }\end{array}$ \\
\hline 1 & Self limited hyponatremia \\
\hline
\end{tabular}

Noticeably, half of all CSH produced midline shift and the majority of these (over 90\%) were successfully managed with steroids.

Twenty-two patients initially treated with dexamethasone ultimately needed a surgical drain and three more needed craniotomy. Interestingly, results in the dexamethasone subgroup of patients were excellent: 97 out of 101 resulted in grades 0-1-2 at discharge. Patients operated on also obtained good outcomes. Mortality was very low for the whole series $(0.8 \%)$ despite the advanced age of the patients. All patients readmitted (14.7\%) did well. Although the overall morbidity figure was high (27.8\%), complications attributable to steroid therapy (mainly hyperglycemias, infections and gastrointestinal bleeding) could be successfully managed in the majority of patients with specific treatment. Dexamethasone therapy had to be abandoned only once because of intolerance. Median follow up (25 weeks) allowed ascertaining a remarkable discrepancy between the rates at which clinical and radiological resolution were achieved, a singular finding that it is discussed below.
Table 7

Risk of developing complications after surgical treatment of CSH

\begin{tabular}{|l|l|}
\hline $2-7 \%$ & Superficial wound infection ${ }^{6,18,24}$. \\
\hline$<2 \%$ & Subdural empyema ${ }^{6,18} \cdot$ \\
\hline Rare & $\begin{array}{l}\text { Ipsi/contralateral acute subdural/epidural hae- } \\
\text { matoma }\end{array}$ \\
\hline Rare & Ipsi/contralateral intracerebral haemorrhage $^{5,6,10}$ \\
\hline$<3 \%$ & Tension pneumocephalus ${ }^{10,18} \cdot$ \\
\hline Rare & Catheter penetration of the brain $^{18,24} \cdot$ \\
\hline $5-25 \%$ & Recurrence $^{6,7,10,11,18-20,24,25,31} \cdot$ \\
\hline $1-10 \%$ & Mortality $^{6,7,10,11,18,19,24,25,31} \cdot$ \\
\hline
\end{tabular}

\section{Pathophysiology of chronic subdural haematoma}

The understanding of the mechanisms involved in the formation of CSH have evolved from the concept of hyperosmotic gradient proposed by Gardner ${ }^{8}$ and supported by Suzuki ${ }^{27}$, to a modern theory of inflammatory processes provoked by repeated subdural bleeding based on experimental studies ${ }^{14,15,16}$. The hyperosmotic gradient theory proposed that the growing of the haematoma is caused by the inflow of plasma fluid inside the forming clot due to its higher osmolality. This would increase the tension of the haematoma capsule and produce rupture of its capillary vessels and bleed inside, thus augmenting the oncotic pressure and attracting more fluid. This theory has been thoroughly discussed and opposed by the studies of Weir et $\mathrm{al}^{32}$. By lowering the pressure inside the haematoma (by inserting a subdural drain, for example) this cycle of events would be interrupted and the fibrosis of the membranes favoured, resulting in the fluid absorbance.

A more dynamic pathophysiologic perspective is proposed by Drapkin ${ }^{6}$ and supported by the experimental studies performed by Ito et $\mathrm{al}^{14}$ and Labadie et $\mathrm{al}^{15,16}$. In their view, the presence of some products from the erythrocyte lysis inside the subdural space, probably as a consequence of the rupture of some cortical bridge veins, induces a local inflammatory response, and a cycle of bleeding-fibrinolysis where neo-membranes and neo-capillaries are involved; a process that may result in the enlargement of the fluid collection. The balance between re-bleeding and the process of absorbance determines the size and the tendency to grow or disappear of the haematoma.

The studies by Vaquero et $\mathrm{al}^{28}$ have demonstrated that the external neo-membrane of the haematoma contains plasmatic cells and macrophages that produce high concentrations of VEGF (Vascular Endothelial Growth Factor) 


\section{Table 8}

Published studies on corticotherapy for CSH

\begin{tabular}{|c|c|c|}
\hline Authors & $\mathbf{N}$ & Outcome \& Comments \\
\hline Ambrosetto C (1962) ${ }^{1}$ & 3 & $\begin{array}{l}\text { The three patients resolved within few months (improved within 2-4 weeks) with a } \\
\text { combination of bed rest, vitamin supplement, corticoids (not specified), intravenous } \\
\text { injection of hypertonic glucose solutions and other drugs. Diagnosis and follow up } \\
\text { done with cerebral angiogram. }\end{array}$ \\
\hline $\begin{array}{l}\text { Bender MB \& } \\
\text { Christoff N }(1974)^{2}\end{array}$ & 27 & $\begin{array}{l}\text { All improved after } 24 \text { hours. Used prednisone } 60 \mathrm{mg} \text { for } 21 \text { days average. Diagnosis } \\
\text { and follow up done with cerebral angiogram. Ten patients }(37 \%) \text { needed surgery } \\
\text { afterwards due to clinical stabilization or deterioration after } 72 \text { hours. }\end{array}$ \\
\hline $\begin{array}{l}\text { Victoratos GC \& } \\
\text { Bligh AS }(1981)^{29}\end{array}$ & 1 & $\begin{array}{l}\text { Dexamethasone (dose not reported) for one week. Headache resolved in } 48 \text { hours. CT } \\
\text { based image follow up. }\end{array}$ \\
\hline $\begin{array}{l}\text { Parajuá M et al } \\
(1984)^{22}\end{array}$ & 3 & $\begin{array}{l}\text { Dexamethasone ( } 16 \mathrm{mg} \text { per day intramuscular). Clinical improvement (immediately } \\
\text { after initiation of steroids) preceded radiological resolution ( } 6,6 \text { and } 4 \text { months after cor- } \\
\text { ticotherapy). Full recovery of all three cases. }\end{array}$ \\
\hline $\begin{array}{l}\text { Inzelberg } \mathrm{R} \text { et al } \\
(1989)^{13}\end{array}$ & 1 & $\begin{array}{l}\text { Intravenous dexamethasone (dose not reported). Complete resolution of hemiparesis } \\
\text { and dysphasia. Patient on anticoagulant medication for haemodialysis. CT based image } \\
\text { follow up. }\end{array}$ \\
\hline $\begin{array}{l}\text { Rudiger A et al } \\
(2001)^{23}\end{array}$ & 1 & $\begin{array}{l}\text { Dexamethasone } 4 \mathrm{mg} / 12 \text { hours. Seventy-six year-old diabetic patient presenting with } \\
\text { confusion and ataxia, harbouring a bilateral CSH. Surgery impossible because of anaes- } \\
\text { thetic problems. Developed hyperglycaemic impairment that needed insulin therapy. } \\
\text { Resolved completely in a few days. CT image normal alter } 6 \text { weeks. }\end{array}$ \\
\hline $\begin{array}{l}\text { Decaux O et al } \\
(2002)^{3}\end{array}$ & 2 & $\begin{array}{l}\text { Cortancyl }{ }^{\circledR} \text { (cortisone } 1 \mathrm{mg} / \mathrm{Kg} / \text { day). Complete early clinical and radiological resolu- } \\
\text { tion. }\end{array}$ \\
\hline $\begin{array}{l}\text { Sun TFD et al } \\
(2005)^{26}\end{array}$ & 26 & $\begin{array}{l}\text { Dexamethasone } 4 \mathrm{mg} / 6 \mathrm{~h} \text { for } 21 \text { days. Patients in old age with medical co-morbidity or } \\
\text { who refused surgical treatment. Twenty-three patients }(84 \%) \text { achieved favourable out- } \\
\text { come. Surgical drain plus steroids reduced the chance of re-accumulation. }\end{array}$ \\
\hline Present series & 101 & $\begin{array}{l}\text { Dexamethasone } 4 \mathrm{mg} / 8 \mathrm{~h} \text {, re-evaluation after } 48-72 \mathrm{~h} \text { and corticoids tapered down. Fa- } \\
\text { vourable results in } 71 / 73 \text { exclusively managed with dexamethasone. Needed surgical } \\
\text { drainage } 22 \text { patients out of } 101 \text {. }\end{array}$ \\
\hline
\end{tabular}

along with bFGF (beta Fibroblast Growth Factor), both of which are recognized angiogenic factors, inside the subdural haematoma. Also, the concentration of PDGF (Platelet Derived Growth Factor, a factor involved in wound healing) inside the haematoma is much less than that of plasma ${ }^{25}$. Consequently, CSH may be considered an angiogenic disease where subacute inflammatory phenomena play a preponderant role.

\section{Rationale for the use of glucocorticoids in chronic sub-}

\section{dural haematoma}

Although corticoids proved to be clinically ineffective in severe head trauma, they have been used in CSH on the basis of their special capacity to block the inflammatory changes occurring in the formation of the haematoma. Glucocorticoids specifically impede the formation of neomembranes and neo-capillaries by their powerful inhibition of inflammatory mediators such as lymphokins and prostaglandins and stimulation of inflammatory inhibitors like 
lipocortin $^{16,25}$. Also, glucocorticoids induce the secretion of the inhibitor of plasminogen, a substance that reduces the cycle rebleeding-lysis of the clot, and reduce the expression of VEGF which inhibits abnormal angiogenesis ${ }^{25}$.

Several authors have empirically and occasionally treated patients with $\mathrm{CSH}$, in which surgical evacuation was contraindicated for some reason, with glucocorticoids or other hyperosmolar agents (glucose, fructose, mannitol) resulting in satisfactory outcomes ${ }^{2,13,29}$. Classically, these medical therapies have been reserved for three scenarios: minimally symptomatic or asymptomatic cases, for minimum radiological and clinical recurrences after surgical drainage and in surgically contraindicated patients. Spontaneous resolutions of untreated CSHs are also reported in the literature $\mathrm{e}^{25,30}$.

\section{Effectiveness of therapeutical options in chronic subdural haematoma}

Previously reported non-operative options include osmotherapy, corticotherapy and even radiotherapy ${ }^{25}$. Sound evidence on the clinical effectiveness of these therapies is lacking since no well-designed trials support their use. Only dexamethasone has been occasionally used based on the experimental studies ${ }^{16}$ in the murine model where neo-membrane inhibition was demonstrated.

There are various surgical and medical options available as it has been recently reviewed by Santarius and Hutchinson $^{25}$, but there is no clear consensus on the best method. Until the notable publication by Markwalder et al ${ }^{17}$ in 1981, craniotomy and membranectomy were frequently used as the method of choice. These authors demonstrated the effectiveness and safety of burr holes plus subdural drains. Since then, several papers have compared this with other less invasive methods, like mini-craniostomy via twist-drill and closed system drainage, approaches that seem to be associated with less morbidity and a similar rate of recurrence ${ }^{7,18,19}$. The randomized study published by Muzzi et $\mathrm{al}^{19}$, showed equal results and morbidity in patients treated by burr hole and those treated by twistdrill, although absorbance of haematic remnants occurred faster, the duration of the procedure was decreased and fewer recurrences were found in the twist-drill group, yet not reaching statistical significance.

Data from the review paper published by Weigel et al ${ }^{31}$ provides relevant information about the effectiveness and safety of surgical therapies. Burr hole is a simple and easyto-perform technique with a low morbidity rate (ranging from 0 to $9 \%$ ) but a rather variable rate of recurrence up to $28 \%{ }^{31}$. There is no sound evidence recommending the use of concomitant subdural drainage or irrigation, although class $\mathrm{C}$ studies support their use as it does not seem to predispose to infection. Probably, a single burr hole with subdural drain to a closed system (minimizing the chance of pnemocephalus) and no irrigation would be the best option in terms of efficacy and safety. A burr hole through a twist-drill method is probably less invasive and equally effective as long as it is followed by drain insertion.

Craniotomy is associated with a similar mortality but much more morbidity as compared to burr hole drainage (although not clearly defined in the literature). At present, craniotomy should be considered only to evacuate solid haematomas and in cases of multiple recurrences. Craniectomy has been used in the context of significant brain swelling after several recurrences, especially when the brain fails to re-expand. Endoscopy is a technique to be considered in multiloculated haematomas where thick membranes need fenestration. Other methods of brain expansion try to diminish the size of the subdural space by hyper-hydrating or infusing certain substances via a lumbar or intraventricular route. It is unclear whether remaining postoperatively in the horizontal or in the Trendelemburg's position makes any difference.

Surgical patient series published so far have shown good to excellent outcomes in the majority of patients. A paradigmatic report of a homogeneous surgical series could be that of Mori and Maeda ${ }^{18}$ on 500 consecutive cases of $\mathrm{CSH}$ operated on over a 12-year period. They performed two burr holes, irrigated the subdural space and inserted a drain to a closed system for 1-2 days. They obtained good results in $89.4 \%$, unchanged in $8.4 \%$ and worsened in $2.2 \%$. The mortality rate was $1.2 \%$, recurrences appeared in $9.8 \%$ and complications occurred in $5.4 \%$ (including several cases of acute subdural haematoma and tension pneumocephalus). They ascertained an increased chance of recurrence when brain re-expansion did not occur. Older patients and those with previous brain infarcts or persistence of postoperative pneumocephalus re-expanded significantly less. The large series published in 2005 by Gelabert-González et al ${ }^{11}$ (1000 patients) showed a morbidity and mortality rate of $19.6 \%$ and $2.1 \%$, respectively. These authors draw the attention to the fact that poor prognosis was related to older age (over 70) and worse clinical grade on admission (grades 3-4).

The problem of the postoperative recurrence of haematomas has been addressed by Gazzeri et $\mathrm{al}^{9}$ who have recently proposed a novel technique consisting in evacuation of the haematoma through a single burr hole and insertion of a Jackson-Pratt drain in the subgaleal space with suction facing the hole in order to continuously draining the remaining haematoma. They had to reoperate only on 17 patients out of 224 (7.6\% recurrence rate) and they report some rather remarkable morbidity and mortality rates of $1.3 \%$ and $0.9 \%$, respectively.

The study by Oishi et $\mathrm{al}^{20}$ showed that the rate of recurrence seems to be related to the density of the haematoma. Thus, hypodense, isodense, hyperdense, those with a level 
of fresh blood and mixed haematomas were associated with recurrence rates of $0 \%, 2.3 \%, 17.2 \%, 12.5 \%$ and $6.5 \%$, respectively. The paper by Weigel et $\mathrm{al}^{31}$, following Evidence Based Medicine criteria, reviews the results of surgical treatments of other studies published from 1981 to 2001, including series of, at least, 10 patients and a follow up no less than $90 \%$. They compared the results of the three most commonly used techniques: burr hole, twist-drill craniostomy and craniotomy. They concluded that burr hole craniostomy has the best cure/complication ratio (class evidence $\mathrm{C}$ ); that irrigating through the mini-burr hole decreases the chance of recurrence and does not increase the rate of infection (class evidence $\mathrm{C}$ ); the insertion of a subdural drain decreases the rate of recurrence without rising the chance of infection (class evidence $\mathrm{C}$ ); that the frontal insertion of the drainage tube decreases the rate of recurrence (class evidence B); that recurrent CSHs are more effectively resolved by burr hole than twist-drill craniostomy (class evidence $\mathrm{C}$ ); and that craniotomy should be reserved for recurrent $\mathrm{CSH}$ as the last choice technique (class evidence C). The authors also remark that clinical results have remained basically unchanged for the last 20 years. No recommendations were done based on class A studies as a result of the literature review.

The effectiveness of surgical treatment has been ascertained in multiple studies ${ }^{10,18,19,24,31}$. The percentage of patients cured with surgery may be as high as $90 \%$ with radiological resolution over $60 \%$ within the first two months. Reported recurrence rates vary between $5 \%$ and $25 \%$. The morbidity and mortality of the series are strongly influenced by the advanced age of the patients and their accompanying co-morbidity. Global mortality rates of 1$5 \%$ are commonly reported but as high as $8-10 \%$ in the population subset over 80 years-old ${ }^{10}$. The morbidity of surgical series is variable and includes complications related to the procedures per se and other linked to previous morbidities and age. An estimation of risks for developing postoperative complications is shown in Table 7 .

\section{Effectiveness of glucocorticoids in chronic subdural hae- matoma}

There is scarce evidence in the literature on the effectiveness of non-surgical treatment of $\mathrm{CSH}$ in general and on the use of glucocorticoids in particular. Only small case series of patients managed with bed rest, hyperosmolar solutions, glucocorticoids or combinations of these have been published so $\mathrm{far}^{30}$. Suzuki et al ${ }^{27}$ reported excellent results with the administration of a $20 \%$ mannitol solution; they obtained complete cure in 22 of 23 patients with no complications or recurrences after 12-106 days follow up. These results were not confirmed by Gjerris and Schmidt ${ }^{12}$ who were forced to interrupt a controlled clinical trial of mannitol in CSH after the ninth patient because of unfavourable results.

Voelker $^{30}$ have reviewed all the available literature about the non-surgical treatment of CSH up to year 2000: only 11 papers including 156 patients treated with combinations of bed rest, glucocorticoids, hypertonic glucose solutions and mannitol. After that date we have found only three more papers on corticotherapy for CSH. Patients mainly or exclusively managed with glucocorticoids are very few ${ }^{1-3,22,23,26,29}$. They are collected in 8 studies as it is shown in Table 8.

To our knowledge, no clinical data other than that exposed in Table 8 is available, as far as the literature is concerned, regarding corticoid therapy of CSH. It is likely that many surgeons have experience with corticoids in $\mathrm{CSH}$ as we have personally ascertained through personal communications in professional meetings with colleges but, unfortunately, unpublished data is not suitable for thorough analysis.

\section{Relevant clinical considerations}

Based upon the clinical experience above described, we are able to summarize certain relevant clinical considerations regarding this therapeutic option:

1. Non-surgical treatment (corticotherapy or others) of $\mathrm{CSH}$ is a feasible option in the view of the literature and our own clinical experience. Corticotherapy is a safe option even in very old patients with important co-morbidity. We were able to obtain good results even in patients harbouring haematomas that produced marked midline shift and presented with neurological defects and depressed level of consciousness. The use of dexamethasone did not preclude other surgical or medical treatments eventually needed.

2. In our view, CSH may not be considered a neurosurgical emergency since no irreversible or abrupt neurological deterioration occurred while the patients were under observation during the dexamethasone protocol follow up (48-72 hours). This medical treatment can be easily initiated by any doctor at any centre, not necessarily in a neurosurgical unit. In our experience, at least two thirds of the patients could be successfully managed with dexamethasone alone, thus avoiding many transfers to neurosurgical centres.

3. Medical therapy eliminates all possible complications related to initial operations or recurrences, many of which can be severe. Complications related to corticotherapy are basically altered hyperglycaemic status that can be easily dealt with in the great majority of cases. Deep venous thrombosis, pulmonary embolism, gastrointestinal bleeding, 
hydro-electrolyte or cardiac impairment occasionally occurred. Their relation to corticotherapy itself is, at least, debatable. Even though an increased rate of nosocomial infections is expected to be attributable to corticoid administration, advanced age and previous co-morbidities may also contribute.

4. There is a discrepancy between the pace of clinical improvement and radiological resolution of the CSH. Early (even in the same day) after the initiation of corticotherapy, many patients experience a remarkable clinical improvement while radiological resolution may take several months. In our experience, the presence of midline shift due to the mass effect from the CSH did not predispose to failure of the medical treatment nor was it related to a worse outcome, independently of the final treatment applied.

5. From the point of view of the patient and his/her family, the possibility of attempting a less invasive medical treatment with a well-known medicament before considering a surgical option is a wellunderstood and appreciated managing practice that did not induce practical problems or ethical issues. It is the patient and his/her family themselves who participate in the decision making process by assessing their own perception about the clinical evolvement during the dexamethasone trial follow up period.

6. Although the present paper does not contemplate an economic analysis, corticotherapy may reduce costs since hospital stay tends to be shorter, the occurrence of severe complications are scarce, the cost of medication is low, the need for interventions is markedly reduced and there is a possibility for outpatient treatment and follow up.

As it is described in the result analysis, we did not strictly follow the scheme presented, for 18 patients in grades 3-4 did not undergo surgery; still, 12 out of the 18 were successfully managed with dexamethasone alone. This violation of the proposed protocol is the result of an increased confidence in the effectiveness of dexamethasone as our clinical experience grew. We progressively dared to treat patients in poor grades after the verification of repeated positive outcomes in this subset of patients.

In our opinion, the only indication for surgery as an initial emergency treatment may be the case of a patient with depressed level of consciousness and severe neurological deterioration occurring acutely. It is possible that even these cases may also benefit from dexamethasone but this fact must be confirmed by others and proved to be safe in a properly designed clinical trial. Given that the natural history of untreated $\mathrm{CSH}$, even in severe cases, it allows, at least, some hours of observation and seems reasonable to propose the steroid trial as the first therapeutic choice.

\section{Conclusions}

This novel therapeutic approach to CSH opposes the traditional view of neurosurgeons that are prone to indicate early surgery supported by good results obtained in thousands of cases before. We do not advocate for the substitution of surgery by steroid medication but to consider glucocorticoids a conservative alternative in the majority of cases. Within the limitations of this retrospective analysis, the effectiveness, safety and applicability of steroids seem comparable to those of surgery and eliminate all possible morbidities of interventions.

Of course, the true role of glucocorticoids in the management of CSH as compared to surgical techniques should be ideally subject of analysis in a multi-centre, prospective, randomized and controlled trial. The clinical profile of the disease makes improbable the existence of ethical issues against the realisation of such study. The preliminary information offered by our retrospective case review may be a starting point for future studies in assessing the real effectiveness and safety of corticotherapy in this disease.

\section{References}

1. Ambrosetto, C.: Post-traumatic subdural hematoma. Further observations on nonsurgical treatments. Arch Neurol 1962; 6: 47-52.

2. Bender, M.B., Christoff, N.: Nonsurgical treatment of subdural hematomas. Arch Neurol 1974; 31: 73-79.

3. Decaux, O., Cador, B., Dufour, T. et al.: Nonsurgical treatment of chronic subdural hematoma with steroids: two cases reports. Rev Med Intern 2002; 23: 788-791.

4. Delgado, P.D., Cogolludo, F.J., Mateo, O., et al.: Pronóstico precoz en hematomas subdurales crónicos. Análisis multivariante de 137 casos. Rev Neurol 2000; 30: 811-817.

5. Díaz, P., Maillo, A.: Hematoma intracerebral tras la evacuación de hematoma subdural crónico: descripción de dos casos y revisión de la literatura. Neurocirugía 2003; 14: 333337.

6. Drapkin, A.J.: Chronic subdural hematoma: pathophysiological basis for treatment. Br J Neurosurg 1991; 5: 467473.

7. Gabarros, A., Acebes, J.J., Rodríguez, R., et al.: Resultados del tratamiento quirúrgico del hematoma subdural crónico. Comparación de dos técnicas: minitrépano y drenaje cerrado continuo versus dos trépanos y drenaje externo abierto. Neurocirugía 2000; 11: 377-390.

8. Gardner, W.J.: Traumatic subdural hematoma with particular reference to the latent interval. Arch Neurol Psychiat 1932; 27: 847-858.

9. Gazzeri, R., Galarza, M., Neroni, M., Canova, A., Refice, G.M., Esposito. S.: Continuous subgaleal suction drainage for the treatment of chronic subdural haematoma. Acta 
Neurochir (Wien) 2007; 149: 487-493.

10. Gelabert, M., Fernández, J.M., López, E., GarcíaAllut, A.: Hematoma subdural crónico en el paciente mayor de 80 años. Neurocirugía 2001; 12: 325-330.

11. Gelabert-González, M., Iglesias-Pais, M., GarcíaAllut, A., Martínez-Rumbo, R.: Chronic subdural haematoma: surgical treatment and outcome in 1000 cases. Clin Neurol Neurosurg 2005; 107: 223-229.

12. Gjerris, F., Schmidt, K.: Chronic subdural hematoma. Surgery or mannitol treatment. J Neurosurg 1974; 40: 639642.

13. Inzelberg, R., Neufeld, M.Y., Reider, I., Gari, P.: Nonsurgical treatment of subdural hematoma in a hemodialysis patient. Clin Neurol Neurosurg 1989; 91: 85-89.

14. Ito, H., Komai, T., Yamamoto, S.: Fibrinolytic enzyme in the lining walls of chronic subdural hematoma. J Neurosurg 1978; 48: 197-200.

15. Labadie, E.L., Glover, D.: Local alterations of hemostatic-fibrinolytic mechanisms in reforming subdural hematomas. Neurology 1975; 25: 669-675.

16. Labadie, E.L., Glover, D.: Physiopathogenesis of subdural hematomas: part II: inhibition of growth of experimental hematomas with dexamethasone. J Neurosurg 1976; 45: 393-397.

17. Markwalder, T.M., Steinsiepe, K.F., Rohner, M., Reichenbach, W., Markwalder, H.: The course of chronic subdural haematomas after burr-hole craniostomy and closed-system drainage. J Neurosurg 1981; 55: 390-396.

18. Mori, K., Maeda, M.: Surgical treatment of chronic subdural hematoma in 500 consecutive cases: clinical characteristics, surgical outcome, complications and recurrence rate. Neurol Med Chir (Tokyo) 2001; 41: 371-381.

19. Muzii, V.F., Bistazzoni, S., Zalaffi, A., Carangelo, B., Mariotini, A., Palma, L.: Chronic subdural hematoma: comparison of two surgical techniques. J Neurosurg Sci 2005; 49: 41-46.

20. Oishi, M., Toyama, M., Tamatani, S., Kitazawa, T., Saito, M.: Clinical factors of recurrent chronic subdural hematoma. Neurol Med Chir (Tokyo) 2001; 41: 382-386.

21. Ortega-Martínez, M., Fernández-Portales, I., Cabezudo, J.M., Rodríguez-Sánchez, J.A., Gómez-Perals, M.F., Giménez-Pando, J.: Parálisis completa del tercer par craneal como forma de presentación en hematoma subdural crónico. Neurocirugía 2003; 14: 423-425.
22. Parajuá, J.L., Goñi, M., Jiménez, M., Feijoo, M.: Tratamiento médico del hematoma subdural crónico. Med Clin (Barc) 1984; 84: 404-406.

23. Rudiger, A., Ronsdorf, A., Merlo, A., Zimmerli, W.: Dexamethasone treatment of a patient with large bilateral chronic subdural haematoma. Swiss Med Wkly 2001; 131: 387.

24. Sambasivan, M.: An overview of chronic subdural hematoma: experience with 2300 cases. Surg Neurol 1997; 47: 418-422.

25. Santarius, T., Hutchinson, P.J.: Chronic subdural haematoma: time to rationalize treatment? Br J Neurosurg 2004; 18: 328-332.

26. Sun, T.F.D., Boet, R., Poon, W.S.: Non-surgical primary treatment of chronic subdural haematoma: preliminary results of using dexamethasone. Br J Neurosurg 2005; 19: 327-333.

27. Suzuki, J., Takaku, A.: Nonsurgical treatment of chronic subdural hematoma. J Neurosurg 1970; 33: 548-553.

28. Vaquero, J., Zurita, M., Cincu, R.: Vascular endotelial growth-permeability factor in granulation tissue of chronic subdural haematomas. Acta Neurochir (Wien) 2002; 144: 343 346.

29. Victoratos, G.C., Bligh, A.S.: A more systematic management of subdural hematoma with the aid of CT scan. Surg Neurol 1981; 15: 158-160.

30. Voelker, J.L.: Nonoperative treatment of chronic subdural hematoma. Neurosurg Clin N Am 2000; 11: 507513.

31. Weigel, R., Schmiedek, P., Krauss, J.K.: Outcome of contemporary surgery for chronic subdural haematoma: evidence based review. J Neurol Neurosurg Psychiatry 2003; 74: 937-943.

32. Weir, B.: Oncotic pressure of subdural fluids. J Neurosurg 1980; 53: 512-515.

Delgado-López, P.D.; Martín-Velasco, V; Castilla-Díez, J.M.; Rodríguez-Salazar, A.; Galacho-Harriero, A.M.; Fernández-Arconada, O.: Dexamethasone treatment in chronic subdural haematoma. Neurocirugía 2009; 20: 346-359.

Correspondencia postal: Dr. Pedro David Delgado López. Servicio de Neurocirugía. Hospital General Yagüe. Avda Cid 96. 09005, Burgos. 